\title{
Ballistic Performance of Natural Fiber Based Soft and Hard Body Armour- A Mini Review
}

\author{
J. Naveen ${ }^{1}$, K. Jayakrishna ${ }^{1}$, Mohamed Thariq Bin Hameed Sultan ${ }^{2,3,4,5 *}$ and \\ Siti Madiha Muhammad Amir ${ }^{6}$
}

${ }^{1}$ School of Mechanical Engineering, Vellore Institute of Technology, Vellore, India, ${ }^{2}$ Laboratory of Biocomposite Technology, Institute of Tropical Forestry and Forest Products (INTROP), Universiti Putra Malaysia, Serdang, Malaysia, ${ }^{3}$ Department of Aerospace Engineering, Faculty of Engineering, Universiti Putra Malaysia, Serdang, Malaysia, ${ }^{4}$ Aerospace Malaysia Innovation Centre (944751-A), Prime Minister's Department, MIGHT Partnership Hub, Cyberjaya, Malaysia, ${ }^{5}$ UPM Press, Universiti Putra Malaysia, Serdang, Malaysia, ${ }^{6}$ Industrial Technology Division, Malaysian Nuclear Agency, Bangi, Kajang, Selangor

\section{OPEN ACCESS}

Edited by: Andrea Dorigato, University of Trento, Italy

Reviewed by: Artur Camposo Pereira, Military Institute of Engineering, Brazil Fabio Da Costa Garcia Filho, University of California San Diego, United States

*Correspondence: Mohamed Thariq Bin Hameed Sultan, thariq@upm.edu.my

Specialty section:

This article was submitted to Polymeric and Composite Materials, a section of the journal Frontiers in Materials

Received: 19 September 2020 Accepted: 20 November 2020 Published: 09 December 2020

Citation:

Naveen J, Jayakrishna K, Hameed Sultan MTB and Amir SMM (2020) Ballistic Performance of Natural Fiber Based Soft and Hard Body Armour- A Mini Review.

Front. Mater. 7:608139. doi: $10.3389 /$ fmats.2020.608139
Increase in awareness towards utilization of eco-friendly materials, encouraged the researchers to find a sustainable alternative to synthetic fibers for different engineering applications. High performance Kevlar fabrics are widely used in ballistic applications such as bullet proof helmets, vest, and other armour systems. Ballistic impact produces shock waves which may cause severe trauma injuries to the soldiers. Kevlar fabric based armour system provides acceptable range of protection to the soldiers. However, disposal of Kevlar affects the eco system and pollutes the environment. Replacing Kevlar fabric in the protective structures with an eco-friendly light weight material, together with an improved kinetic energy absorption and dissipation has become an interesting approach to enhance the ballistic performance of the composite panels. This mini review addresses the effect of adding different natural fibers on the ballistic performance of soft and multilayered hard body armour systems. Many researchers explored the possibility of utilizing eco-friendly natural fibers (Kenaf, Cocos nucifera sheath, Malva, rami, curaua, bagasse, jute, bamboo) as an alternate material to Kevlar fabric in the armour system and reported that natural fibers can act as a potential reinforcement in the ballistic structures.

Keywords: synthetic fiber, natural fiber, polymer composites, ballistic performance, soft body armour, hard body armour

\section{INTRODUCTION}

Ancient body armours were made by using plant fiber or animal hide. After the arrival of metallic materials, body armors have been made as a plate by using iron, copper, and steel. Nonetheless, innovations in material science in the 20th century have led to the discovery of high performance synthetic fibers and its composites (Hani et al., 2012). Synthetic fiber reinforced polymeric composites offer many advantages such as higher specific strength, stiffness, corrosion resistance and enhanced fatigue properties compared to conventional metallic materials.

Aramid fiber based polymeric composites are widely used in ballistic applications such as bullet proof helmets, body armour vest, and other armor systems due to its ability to resist high kinetic energy projectiles. Even though these aramid fibre composites having higher specific strength, impact strength and corrosion resistance most of the fibres are manufactured from petroleum based resources (Naveen et al., 2019). Depletion of petroleum based resources urges the researchers to find 


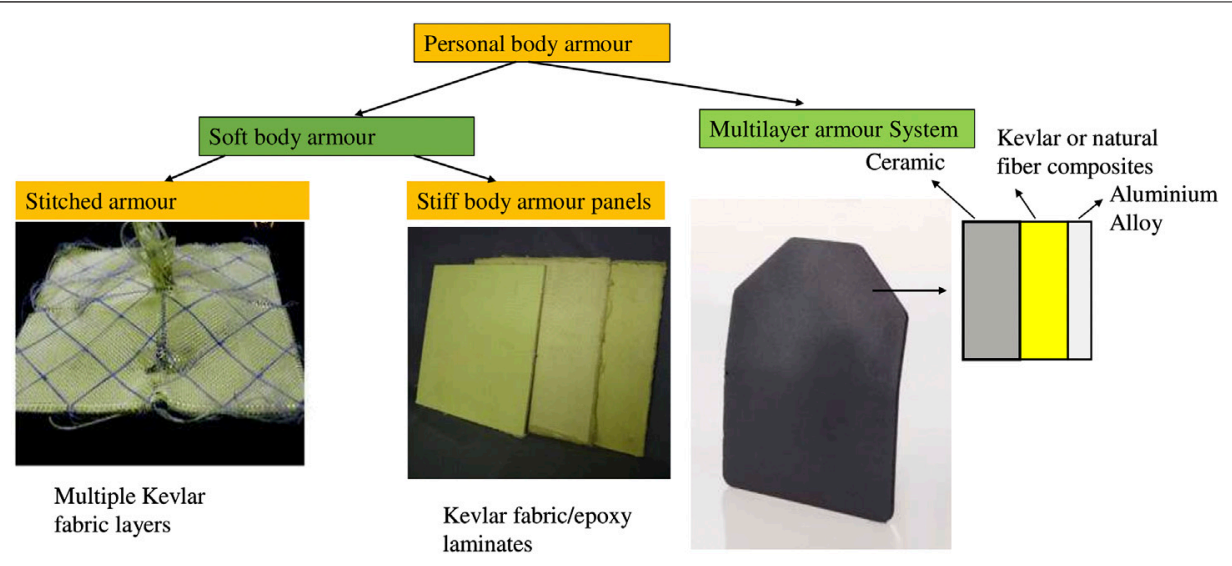

FIGURE 1 | Classification of body armour system. Roy et al. (2019)

a sustainable replacement. Moreover, disposal of Aramid fiber pollutes the environment (Jesuarockiam et al., 2019). Hence, it is imperative to find an alternate material to man-made synthetic fiber for armour applications.

The utilization of natural fibers have been encouraged by "end of life" regulation in Europe and Asia (Holbery and Houston, 2006). The main advantages of using natural fibers are low density, nonabrasive, non-corrosive, inherent biodegradability, low cost, higher specific strength and stiffness, easily available and recyclable. Moreover, while comparing the cost of commercial armour material (Dyneema), natural fibers can reduce the cost upto $70 \%$. The possibility of utilizing natural fibers for ballistic applications were explored (Benzait and Trabzon, 2018; Monteiro et al., 2019). It has been found that plant fibers or natural fibers can act as an alternative and sustainable replacement to synthetic fibers in both soft armour panels and multilayer armour system (MAS).

Ballistic impact produces shock waves which may cause severe trauma injuries to the soldiers (Naveen et al., 2019). MAS are the efficient personal protective system against high kinetic energy ballistic threats (7.62 mm caliber). Generally, MAS consist of ceramics ( $\mathrm{SiC})$, composites (Kevlar/epoxy) and metal (Al). On the other hand, the monolithic armour vests which are made up of aramid fabrics or steel required a large thickness. It predominantly affects the mobility and comfort of the wearer. Hence, the combination of ceramics, composites and metal could be the effective solution.

The notion of this review is to analyze the ballistic performance in terms of energy absorption, limit velocity and depth of indentation of natural fiber based soft and multilayer armour system. Also, this review addresses the different types of body armours, different standards of armour testing according NIJ standards.

\section{CLASSIFICATION OF BODY ARMOUR}

Generally, different fabrication methodologies were employed to produce efficient body armour depending upon the threat type and velocity. Figure 1 shows the different types and fabrication techniques of body armour panels. Personal body armour could be classified into soft armour and hard armour. Soft body armours are further classified into stitched and stiff armour. Stitched armour contains multiple layers of fabrics up to 50 layers and weighs below $4.5 \mathrm{~kg}$, while the stiff armour panels were made with Kevlar fabrics reinforced in the epoxy matrix (Naveen et al., 2018). Generally, the stiff body armour panels were fabricated by using a simple hand lay-up method followed by hot pressing at $105^{\circ} \mathrm{C}$ temperature with 275 bar pressure for $1 \mathrm{~h}$. Soft body armour has to bear the impact velocity up to $500 \mathrm{~m} / \mathrm{s}$. MAS are made with different combinations such as ceramics/ composites, ceramics/metal, composites/metal and ceramics/ composites/metal. The ceramics/composites/metal has been widely used in defence sectors. Ceramics are well-known for its ballistic performance and it has been used as a striking face to improve the effectiveness of the multilayer armour. The second composites layer absorbs and dissipate the kinetic energy of ballistic threats or projectiles. The aramid fabrics (Kevlar ${ }^{\mathrm{TM}}$ and Twaron $^{\mathrm{TM}}$ ) and ultrahigh molecular weight polyethylene $\left(\right.$ Spectra $^{\mathrm{TM}}$ and Dyneema ${ }^{\mathrm{TM}}$ ) are the most commonly used second layer in the multilayer armour. The third metallic layer further stops the impact energy carried by the projectile. These three layers were joined together with polyurethane adhesives (Monteiro et al., 2016).

\section{STANDARDS AND TESTING}

The armour panels has to stop the projectile and it should absorb the kinetic energy of the projectile according to NIJ standards (0101.06) IIA, II, IIIA, III and IV. The velocities for different levels are as follows, Level IIA $(373 \mathrm{~m} / \mathrm{s})$, level II $(436 \mathrm{~m} / \mathrm{s})$, level III $(448 \mathrm{~m} / \mathrm{s})$, level IIIA $(847 \mathrm{~m} / \mathrm{s})$ and level IV $(878 \mathrm{~m} / \mathrm{s})$. Ballistic testing investigates the energy absorption, ballistic limit and depth of indentation or blunt trauma. Different varieties of ballistic limit velocities are $V_{0}$ (maximum velocity with no penetration), $V_{50}$ (50\% probability of complete penetration), and $V_{100}(100 \%$ penetration) (Naveen et al., 2018). Ballistic limit and energy absorption can be calculated using Eqs 1, 2 


$$
\begin{aligned}
V_{50} & =\sqrt{V_{s}^{2}-V_{r}^{2}}, \\
E_{a b s} & =\frac{m v_{s}^{2}-m v_{r}^{2}}{2},
\end{aligned}
$$

where $V_{s}$ is the striking velocity; $V_{r}$ is the residual velocity.

During ballistic testing according to NIJ standards the Multilayer armour system has to be fixed over a ROMA Plastilina block or clay witness. This clay witness simulates the human body being secured by the multilayer armour and should carry the shock waves up to a standard back face signature limit of $44 \mathrm{~mm}$. Beyond this depth of indentation in the ROMA Plastilina block will lead to severe blunt trauma (Monteiro et al., 2016).

Composites structures are subjected to different loading condition during its service life. However, the composite panels for armour applications and protective structure's should resist the high kinetic energy projectiles and ballistic threats (Naveen et al., 2018). Depending on the velocity, impact can be categorized into four different types such as; 1) low velocity impact $(<30 \mathrm{~m} / \mathrm{s}), 2)$ high velocity impact $(30-200 \mathrm{~m} / \mathrm{s})$, 3) ballistic impact $(>200 \mathrm{~m} / \mathrm{s})$ and 4) hyper velocity impact $(15000 \mathrm{~m} / \mathrm{s})$ (Loganathan et al., 2019) During low velocity impact the contact period of the projectile or impactor is longer compared to the duration of lowest vibrational mode. The impact waves move towards the edges of composite panels causing its full vibrational response. On the contrary, in ballistic or high velocity impact the contact duration of the impactor is much lower than the contact period of the lowest vibration mode. On the other hand, at hyper velocity impact the target behaves like fluids.

\section{NATURAL FIBER BASED SOFT ARMOUR SYSTEM}

Hybrid composites provide superior properties. Different hybrid combinations are as follows 1) two or more reinforcing phases embedded in a single continuous phase (matrix), 2) Single reinforcing phase embedded with two or more matrices 3) Two or more reinforcement incorporated in multiple matrices. The main advantage of hybrid composites relies on the fact that the benefit of one type of constituent could surpass the limitations of the other constituent Hybrid ballistic panels were made up of two or more high performance synthetic fibers.

Hybrid synthetic/cellulosic fiber-based laminated composites combine the advantages of individual layers. Replacing Kevlar fabric in the body armors with an eco-friendly light weight material, together with an improved kinetic energy absorption and dissipation has become an interesting approach to enhance the body armors ballistic performance (Naveen et al., 2019). Fibers which possess higher ballistic resistance and lower density are the most promising alternative to Kevlar fabric.

Garicia et al. studied the effect of different volume fraction of Piassava fibers $(10,20,30,40$, and $50 \mathrm{Vf})$ on the energy absorption and limit velocity of Pissava fiber/epoxy composites using a $7.62 \mathrm{~mm} \mathrm{M1}$, full metal jacketed bullet with $9.7 \mathrm{~g}$. It was observed that the composites samples with $10 \mathrm{Vf}$ of Pissava fiber exhibited excellent ballistic performance compared to $\operatorname{Kevlar}^{\mathrm{TM}}$ (Garcia Filho et al., 2020).

Naveen et al. (2018) investigated the ballistic performance of Kevlar, hybrid Kevlar/coconut sheath and coconut sheath based epoxy composites. The velocity range was in between 300 and $330 \mathrm{~m} / \mathrm{s}$. Two stage gas gun has been together with a high speed camera has been utilized to find the impact velocity and residual velocity of the projectile. It has been observed that coconut sheath can act as an efficient alternative to Kevlar fabric in the epoxy composites for ballistic applications. Also it was found that the moderate interfacial properties are essential to achieve better ballistic performance. However, addition of graphene nanoplatelets in the Kevlar/coconut sheath composites did not show much improvement on the ballistic performance due to improved interfacial interaction which is not suitable for ballistic application (Naveen et al., 2019).

FRP composites for high velocity impact or ballistic applications require high specific strength and stiffness, impact resistance, crack resistance and low density. Interestingly, the requirements of ballistic composites differ from other structural laminated composites. The properties of ballistic composites include moderate fiber/matrix adhesion, higher fiber loading, moderate fiber impregnation and voids. Also, the shape and size of the projectile plays an important role in the energy absorption, ballistic limit, and life of the body armor (Naveen et al., 2018) On the other hand, ballistic performance of body armor also depends upon the fiber loading, weaving nature or architecture, panel thickness, and the layering sequence. It has been found that the fibers exhibited different failure modes depending upon their layering pattern and location in the thickness direction, when it is subjected to ballistic impact. During ballistic impact, top layer of the ballistic panel exhibited shear failure while the bottom layer has failed through tensile mode of failure. Hence, while hybridizing different materials, optimized layering sequence of different laminas takes the advantage of individual constituents and consequently improved the ballistic performance of the composite panel (Naveen et al., 2018). Table 1 shows the reported literatures on the ballistic performance of hybrid synthetic/natural composites.

\section{NATURAL FIBER BASED MULTILAYER ARMOUR SYSTEM}

Now a days, combination of ceramic, composites and metallic armour has been preferred due to its combined advantages such as ballistic efficiency, light weight and cost (Monteiro et al., 2015). Generally, synthetic fiber based composites were utilized as a middle layer. Nonetheless, in order to reduce the utilization of synthetic fibers, natural fiber based materials are incorporated in the polymeric matrix. Also, nano filler modified polymeric composites and nano filler coated fiber reinforced polymeric composites has been used as a middle layer. The third metallic layer further stops the impact energy carried by the projectile.

Several studies were conducted by incorporating natural fiber composites as a mid layer in the Multilayer armour system. 
TABLE 1 | Ballistic performance of Natural fiber based soft and hard armours.

\begin{tabular}{|c|c|c|c|c|c|c|}
\hline \multirow[t]{2}{*}{ SI.No } & \multicolumn{5}{|c|}{ Natural fiber based stiff/soft armours } & \multirow[t]{2}{*}{ References } \\
\hline & Fiber & Matrix & \multicolumn{2}{|c|}{ Energy absorption (J) } & Ballistic limit (m/s) & \\
\hline 1 & Kenaf/Kevlar (30/70) & Epoxy & \multicolumn{2}{|l|}{148} & - & Jambari et al. (2017) \\
\hline 2 & Kenaf/Kevlar (Vf6/Vf 47) & Epoxy & \multicolumn{2}{|c|}{175} & 590 & Yahaya et al. (2016) \\
\hline 34 & Coconut sheath/Kevlar (wt\% 5/25) & Epoxy & \multicolumn{2}{|c|}{240} & - & Naveen et al. (2018a) \\
\hline 3 & Curaua fiber (30 Vf)/epoxy composites & Epoxy & \multicolumn{2}{|c|}{197} & - & de Oliveira Braga et al. (2017b) \\
\hline 4 & Kevlar/Basalt $(50 / 50)$ & Polypropylene & \multicolumn{2}{|c|}{112} & - & Bandaru et al. (2016) \\
\hline 5 & Piassava fiber (10 vf) & Epoxy & \multicolumn{2}{|c|}{$272 \pm 19 \mathrm{~J}$} & $236 \pm 8$ & Garcia Filho et al. (2020) \\
\hline 6 & Fique fiber & Polyester & \multicolumn{2}{|c|}{$155 \pm 7$} & - & Pereira et al. (2019a) \\
\hline 7 & Fique fabric & Polyester & \multicolumn{2}{|c|}{$154 \pm 5$} & & \\
\hline & & Natural fiber & ed multilayer a & Irmour system & & \\
\hline $\begin{array}{l}\text { Striking face } \\
\text { (front) }\end{array}$ & Middle lay & & Rear plate & $\begin{array}{c}\text { Back face } \\
\text { signature or } \\
\text { depth of } \\
\text { ndentation }(\mathrm{mm})\end{array}$ & $\begin{array}{l}\text { Recommended NIJ } \\
\text { level (44 mm) }\end{array}$ & References \\
\hline Ceramic (SiC) & Kevlar & & Al alloy & 23 & 44 & Luz et al. (2020) \\
\hline & Dyneema & & & 42 & & \\
\hline & Pineapple leaf fiber/epoxy composit & & & 26 & & \\
\hline & Sugarcane bagasse/epoxy composi & & & 39 & & Monteiro et al. (2016a) \\
\hline & Mallow fiber (aligned)/epoxy compos & & & 22 & & Nascimento et al. (2017a) \\
\hline & Mallow fabric/epoxy composites & & & 22 & & Nascimento et al. (2017b) \\
\hline & Bamboo/epoxy composites & & & 19 & & Cruz et al. (2015) \\
\hline & Sisal/Epoxy composites & & & 12 & & Rohen et al. (2015) \\
\hline & Sisal/Polyester composites & & & 23 & & Braga et al. (2017) \\
\hline & Ramie fiber/epoxy composites & & & 18 & & de Oliveira Braga et al. (2018) \\
\hline & Ramie fabric/epoxy composites & & & 17 & & Monteiro et al. (2016b) \\
\hline & Coir fiber (aligned) epoxy composite & & & 32 & & da Luz et al. (2018) \\
\hline & Coir mat/epoxy composites & & & 24 & & Luz et al. (2017) \\
\hline & Jute fabric/polyester composites & & & 17 & & Monteiro et al. (2018) \\
\hline & Jute fabric/epoxy composites & & & 21 & & Luz et al. (2015) \\
\hline & Jute nonwoven mat/polyester comp & & & 24 & & de Assis et al. (2018) \\
\hline & Curaua aligned/epoxy composites & & & 22 & & Monteiro et al. (2015) \\
\hline & Curaua mat/epoxy composites & & & 28 & & de Oliveira Braga et al. (2017a) \\
\hline & Curaua/polyester & & & 22 & & \\
\hline & $\begin{array}{l}\text { Graphene oxide coated curaua fiber } \\
\text { composite }\end{array}$ & orced epoxy & & 27.4 & & Costa et al. (2019) \\
\hline & Piassava fiber/epoxy & & & 15.6 & & Garcia Filho and Monteiro (2019) \\
\hline & Fique fiber/polyester composites & & & 16 & & Pereira et al. (2019b) \\
\hline & Epoxy-15\% Fique fabric & & & 20 & & Oliveira et al. (2019) \\
\hline
\end{tabular}

Table 1 shows the reported literatures of natural fiber based Multilayer armour system. The recommended depth of indentation or back face signature according to NIJ standard is $44 \mathrm{~mm}$ ( $L u z$ et al., 2020). compared the pineapple/epoxy composites based multilayer armour with dyneema based hard armour plate. For each test $7.62 \mathrm{~mm}$ caliber was utilized with an impact velocity of $849 \mathrm{~m} / \mathrm{s}$. The distance between the multilater armour target and the test weapon was around $15 \mathrm{~m}$. They observed that pineapple leaf fiber composites can efficiently replace the dyneema, since it exhibited a back face signature of $26 \mathrm{~mm}(<44 \mathrm{~mm})$.

Researchers investigated the ballistic performance of ramie fabric/epoxy composites based multilayer amour system. Different vol\% of ramie fabric were embedded in epoxy matrix and the composite samples were incorporated as a middle layer in the multilayer armour system. Ballistic testing was conducted with $7.62 \mathrm{~mm}$ caliber at $849 \mathrm{~m} / \mathrm{s}$. The results revealed that ramie fabric based multilayer armour system exhibited $10-20 \%$ smaller back face signature or blunt trauma compared to Kevlar/epoxy composites based multilayer armour system (Monteiro et al., 2016). Similarly, the blunt trauma or back face signature of several natural fiber based multilayer armours were compared with each other (Table 1). From the critical comparison, it is clear that the plant fiber based sustainable materials can be an effective alternative for man-made synthetic fibers.

\section{CONCLUSION}

Several researchers explored the possibility of utilizing natural fiber based soft and hard body armour panels. The following conclusions were drawn;

- Energy absorption and ballistic limit of natural fiber reinforced polymeric composites are almost matches with high performance aramid fabric composites. 
- The striking face of the composite panels has to be designed to withstand the shear plugging whereas the rear side should resist the tensile failure.

- The major difference between soft and hard body armour is that the soft/stiff armor has to bear the impact velocity of $500 \mathrm{~m} / \mathrm{s}$, where as Multilayer hard armour system should withstand the impact of the projectile more than $500 \mathrm{~m} / \mathrm{s}$ when worn in conjunction with soft armor.

- Natural fiber based Multilayer armour systems exhibited lower depth of indentation compared to Kevlar based multilayer armour.

Hence, it is concluded that natural fiber based sustainable armour panels can be efficiently utilized in both soft and Multilayer hard body armours.

\section{FUTURE RECOMMENDATIONS}

- As per NIJ level 3 standards the armour panel should not fail for six shots. Nonetheless, most of the natural fiber based hardbody armours were tested for only one shot. Extensive research is required to improve the ballistic performance of natural fiber based multilayer armours in order to commercialize the armour panels.

- On the other hand, the middle composite layer was made with non-biodegradable polymeric composites. Due to eco legislation and awareness towards creating green armours

\section{REFERENCES}

Bandaru, A. K., Patel, S., Sachan, Y., Alagirusamy, R., Bhatnagar, N., and Ahmad, S. (2016). Low velocity impact response of 3D angle-interlock Kevlar/basalt reinforced polypropylene composites. Mater. Des. 105, 323-332. doi:10. 1016/j.matdes.2016.05.075

Benzait, Z., and Trabzon, L. (2018). A review of recent research on materials used in polymer-matrix composites for body armor application. J. Compos. Mater. 52 (23), 3241-3263. doi:10.1177/0021998318764002

Braga, F. d. O., Bolzan, L. T., Ramos, F. J. H. T. V., Monteiro, S. N., Lima, É. P., Jr., and Silva, L. C. d. (2017). Ballistic efficiency of multilayered armor systems with sisal fiber polyester composites. Mater. Res. 20, 767-774. doi:10.1590/19805373-MR-2017-1002

Costa, U. O., Nascimento, L. F. C., Garcia, J. M., Monteiro, S. N., Luz, F. S. d., Pinheiro, W. A., et al. (2019). Effect of graphene oxide coating on natural fiber composite for multilayered ballistic armor. Polymers 11 (8), 1356. doi:10.3390/ polym 11081356

Cruz, R. B. d., Lima Junior, E. P., Monteiro, S. N., and Louro, L. H. L. (2015). Giant bamboo fiber reinforced epoxy composite in multilayered ballistic armor. Mater. Res. 18, 70-75. doi:10.1590/1516-1439.347514

da Luz, F. S., Ramos, F. J. H. T. V., Nascimento, L. F. C., da Silva Figueiredo, A. B.H., and Monteiro, S. N. (2018). Critical length and interfacial strength of PALF and coir fiber incorporated in epoxy resin matrix. J. Mater. Res. Technol. 7 (4), 528-534. doi:10.1016/j.jmrt.2018.04.025

de Assis, F. S., Pereira, A. C., da Costa Garcia Filho, F., Lima, É. P., Jr., Monteiro, S. N., and Weber, R. P. (2018). Performance of jute non-woven mat reinforced polyester matrix composite in multilayered armor. J. Mater. Res. Technol. 7 (4), 535-540. doi:10.1016/j.jmrt.2018.05.026

de Oliveira Braga, F., Bolzan, L. T., da Luz, F. S., Lopes, P. H. L. M., Lima, É. P., Jr., and Monteiro, S. N. (2017a). High energy ballistic and fracture comparison between multilayered armor systems using non-woven curaua fabric composites and aramid laminates. J. Mater. Res. Technol. 6 (4), 417-422. doi:10.1016/j.jmrt.2017.08.001 encouraged the researchers to utilize biodegradable polymeric composites.

- The performance of the natural fiber based armour panels can be improved with shear thickening fluid or with multifunctional nano fillers.

\section{AUTHOR CONTRIBUTIONS}

$\mathrm{NJ}$ initiated and wrote the manuscript with input from MS; $\mathrm{JK}$ and SA collected the data and proof read the manuscript.

\section{FUNDING}

The authors would like to thank Universiti Putra Malaysia for the financial support through the Geran Putra Berimpak (GPB9668200).

\section{ACKNOWLEDGMENTS}

We are thankful to School of Mechanical Engineering VIT university India, Department of Aerospace Engineering, Faculty of Engineering, Universiti Putra Malaysia and Laboratory of Biocomposite Technology, Institute of Tropical Forestry and Forest Product (INTROP), Universiti Putra Malaysia for doing this research.

de Oliveira Braga, F., Bolzan, L. T., Lima, É. P., Jr., and Monteiro, S. N. (2017b). Performance of natural curaua fiber-reinforced polyester composites under $7.62 \mathrm{~mm}$ bullet impact as a stand-alone ballistic armor. J. Mater. Res. Technol. 6 (4), 323-328. doi:10.1016/j.jmrt.2017.08.003

de Oliveira Braga, F., Milanezi, T. L., Monteiro, S. N., Louro, L. H. L., Gomes, A. V., and Lima, É. P., Jr (2018). Ballistic comparison between epoxy-ramie and epoxy-aramid composites in multilayered armor systems. J. Mater. Res. Technol. 7 (4), 541-549. doi:10.1016/j.jmrt.2018.06.018

Garcia Filho, F. D. C., and Monteiro, S. N. (2019). Piassava fiber as an epoxy matrix composite reinforcement for ballistic armor applications. J. Occup. Med. 71 (2), 801-808. doi:10.1007/s11837-018-3148-x

Garcia Filho, F. D. C., Oliveira, M. S., Pereira, A. C., Nascimento, L. F. C., Matheus, J. R. G., and Monteiro, S. N. (2020). Ballistic behavior of epoxy matrix composites reinforced with piassava fiber against high energy ammunition. J. Mater. Res. Technol. 9 (2), 1734-1741. doi:10.1016/j.jmrt.2019.12.004

Hani, A., Roslan, A., Mariatti, J., and Maziah, M. (2012). Body armor technology: a review of materials, construction techniques and enhancement of ballistic energy absorption. Trans Tech Publ. 488-489, 806-812.

Holbery, J., and Houston, D. (2006). Natural-fiber-reinforced polymer composites in automotive applications. J. Occup. Med. 58 (11), 80-86. doi:10.1007/s11837006-0234-2

Jambari, S., Yahya, M. Y., Abdullah, M. R., and Jawaid, M. (2017). Woven Kenaf/ Kevlar hybrid yarn as potential fiber reinforced for anti-ballistic composite material. Fibers Polym. 18 (3), 563-568. doi:10.1007/s12221-017-6950-0

Jesuarockiam, N., Jawaid, M., Zainudin, E. S., Thariq Hameed Sultan, M., and Yahaya, R. (2019). Enhanced thermal and dynamic mechanical properties of synthetic/natural hybrid composites with graphene nanoplateletes. Polymers 11 (7), 1085. doi:10.3390/polym11071085

Loganathan, T. M., Sultan, M., Gobalakrishnan, M. K., and Muthaiyah, G. (2019). "Ballistic impact response of laminated hybrid composite materials," in Mechanical and physical testing of biocomposites, fibre-reinforced composites and hybrid composites. Amsterdam, Netherlands: Elsevier, 171-191.

Luz, F. S. d., Garcia Filho, F. d. C., Oliveira, M. S., Nascimento, L. F. C., and Monteiro, S. N. (2020). Composites with natural fibers and conventional 
materials applied in a hard armor: a comparison. Polymers 12 (9), 1920. doi:10. 3390/polym 12091920

Luz, F. S. d., Lima Junior, E. P., Louro, L. H. L., and Monteiro, S. N. (2015). Ballistic test of multilayered armor with intermediate epoxy composite reinforced with jute fabric. Mater. Res. 18, 170-177. doi:10.1590/1516-1439.358914

Luz, F. S. d., Monteiro, S. N., Lima, E. S., and Lima Júnior, É. P. (2017). Ballistic application of coir fiber reinforced epoxy composite in multilayered armor. Mater. Res. 20, 23-28. doi:10.1590/1980-5373-mr-2016-0951

Monteiro, S. N., Candido, V. S., Braga, F. O., Bolzan, L. T., Weber, R. P., and Drelich, J. W. (2016a). Sugarcane bagasse waste in composites for multilayered armor. Eur. Polym. J. 78, 173-185. doi:10.1016/j.eurpolymj. 2016.03.031

Monteiro, S. N., Drelich, J. W., Lopera, H. A. C., Nascimento, L. F. C., da Luz, F. S., da Silva, L. C., et al. (2019). Natural fibers reinforced polymer composites applied in ballistic multilayered armor for personal protection-an OverviewGreen materials engineering. Berlin, Germany: Springer.

Monteiro, S. N., Louro, L. H. L., Trindade, W., Elias, C. N., Ferreira, C. L., de Sousa Lima, E., et al. (2015). Natural curaua fiber-reinforced composites in multilayered ballistic armor. Metall. Mater. Trans. 46 (10), 4567-4577. doi:10.1007/s11661-015-3032-z

Monteiro, S. N., Milanezi, T. L., Louro, L. H. L., Lima, É. P., Jr, Braga, F. O., Gomes, A. V., et al. (2016b). Novel ballistic ramie fabric composite competing with $\operatorname{Kevlar}^{\mathrm{TM}}$ fabric in multilayered armor. Mater. Des. 96, 263-269. doi:10.1016/j. matdes.2016.02.024

Monteiro, S. N., Pereira, A. C., Ferreira, C. L., Pereira, É., Jr., Weber, R. P., and Assis, F. S. d. (2018). Performance of plain woven jute fabric-reinforced polyester matrix composite in multilayered ballistic system. Polymers 10 (3), 230. doi:10.3390/polym 10030230

Nascimento, L. F. C., Louro, L. H. L., Monteiro, S. N., Gomes, A. V., Júnior, É. P. L., and Marçal, R. L. S. B. (2017a). Ballistic performance in multilayer armor with epoxy composite reinforced with malva fibers," in Proceedings of the 3rd Pan American materials congress, (Berlin, Germany: Springer).

Nascimento, L. F. C., Louro, L. H. L., Monteiro, S. N., Lima, É. P., and da Luz, F. S. (2017b). Mallow fiber-reinforced epoxy composites in multilayered armor for personal ballistic protection. J. Occup. Med. 69 (10), 2052-2056. doi:10.1007/ s11837-017-2495-3

Naveen, J., Jawaid, M., Zainudin, E., Sultan, M. T., and Yahaya, R. (2018a). Evaluation of ballistic performance of hybrid Kevlar ${ }^{\circledR} /$ Cocos nucifera sheath reinforced epoxy composites. J. Textil. Inst. 110 (8), 1-11. doi:10.1080/00405000.2018.1548801

Naveen, J., Jawaid, M., Zainudin, E., Sultan, M. T., and Yahaya, R. B. (2018b). Selection of natural fiber for hybrid kevlar/natural fiber reinforced polymer composites for personal body armor by using analytical hierarchy process. Front. Mater. 5, 52. doi:10.3389/fmats.2018.00052/full

Naveen, J., Jawaid, M., Zainudin, E., Sultan, M. T., and Yahaya, R. (2019). Effect of graphene nanoplatelets on the ballistic performance of hybrid Kevlar/Cocos nucifera sheath-reinforced epoxy composites. Textil. Res. J. 89 (21-22), 4349-4362. doi:10.1177/0040517519833970

Oliveira, M. S., da Costa Garcia Filho, F., Pereira, A. C., Nunes, L. F., da Luz, F. S., de Oliveira Braga, F., et al. (2019). Ballistic performance and statistical evaluation of multilayered armor with epoxy-fique fabric composites using the Weibull analysis. J. Mater. Res. Technol. 8 (6), 5899-5908. doi:10.1016/j.jmrt.2019.09.064

Pereira, A. C., Assis, F. S. d., Garcia Filho, F. d. C., Oliveira, M. S., Lima, E. S., Lopera, H. A. C., et al. (2019a). Evaluation of the projectile's loss of energy in polyester composite reinforced with fique fiber and fabric. Mater. Res. 22. doi:10.1590/1980-5373-mr-2019-0146

Pereira, A. C., de Assis, F. S., da Costa Garcia Filho, F., Oliveira, M. S., da Cruz Demosthenes, L. C., Lopera, H. A. C., et al. (2019b). Ballistic performance of multilayered armor with intermediate polyester composite reinforced with fique natural fabric and fibers. J. Mater. Res. Technol. 8 (5), 4221-4226. doi:10.1007/978-3-030-10383-5_18

Rohen, L. A., Margem, F. M., Monteiro, S. N., Vieira, C. M. F., Madeira de Araujo, B., and Lima, E. S. (2015). Ballistic efficiency of an individual epoxy composite reinforced with sisal fibers in multilayered armor. Mater. Res. 18, 55-62. doi:10. 1590/1516-1439.346314

Roy, R., Majumdar, A., and Butola, B. S. (2019). Comparative study of P-aramid based soft and stiff composite panels for protective application. Fibers Polym. 20, 406-412.

Yahaya, R., Sapuan, S., Jawaid, M., Leman, Z., and Zainudin, E. (2016). Investigating ballistic impact properties of woven kenaf-aramid hybrid composites. Fibers Polym. 17 (2), 275-281. doi:10.1007/s12221-016-5678-6

Conflict of Interest: The authors declare that the research was conducted in the absence of any commercial or financial relationships that could be construed as a potential conflict of interest.

Copyright (c) 2020 Naveen, Jayakrishna, Hameed Sultan and Amir. This is an openaccess article distributed under the terms of the Creative Commons Attribution License (CC BY). The use, distribution or reproduction in other forums is permitted, provided the original author(s) and the copyright owner(s) are credited and that the original publication in this journal is cited, in accordance with accepted academic practice. No use, distribution or reproduction is permitted which does not comply with these terms. 